\title{
The structure of Albanian personality descriptive trait-adjectives: A psycho-lexically based taxonomy
}

\author{
Rudina Ademi Shala ${ }^{1}$, Boele De Raad ${ }^{2}$, and Aliriza Arënliu ${ }^{3}$ \\ ${ }^{1}$ University of Prishtina, Hasan Prishtina, Kosovo \\ ${ }^{2}$ University of Groningen, Groningen, The Netherlands \\ ${ }^{3}$ University of Prishtina, Hasan Prishtina, Kosovo
}

\begin{abstract}
In this study, we describe the taxonomy of personality descriptive trait terms in the Albanian language according to the psycho-lexical procedure, in two parts. In the first part the selection of trait terms from a standard Albanian dictionary took place, largely according to standard procedures. This resulted in a useful set of 607 personality relevant terms. In the second part this list of trait terms was administered to 497 participants to obtain self-ratings. During the rating process, participants could indicate their familiarity with the terms, leading to another reduction to a final set of 434 trait terms with self-ratings. Principal Components Analysis followed by Varimax rotation was applied both using raw data and using ipsatized data. Structures with one up to seven factors were discussed and represented in a hierarchy of factor solutions. As an aid to the interpretation of the factors, use was made of markers of the Big Five, selected from the full list of 434 terms. The most comprehensive and clearest structure was found with seven factors, which included the Big Five and both Negative Valence and Positive Valence.
\end{abstract}

Keywords: trait-taxonomy, psycho-lexical approach, personality, trait structure, Big Five

The number of psycho-lexical personality trait studies in countries where especially Indo-European languages are spoken, have increased, up to a level that, with the exception of the Asian branches, most or all languages with at least ten million speakers have been exploited. A few languages with less than ten million speakers have not been studied for personality traits using the psycho-lexical approach, including Catalan, Danish, Swedish, Slovak, Bosnian, Albanian, and Armenian. Of special interest in this latter group of languages is Albanian which is classified as a separate branch of the Indo-European languages showing no obvious close affinity to any other Indo-European language; it is plainly the sole modern survivor of its own subgroup (Fortson, 2011).

Albanian is spoken by about 8 million people (Klein, Joseph, \& Fritz, 2018), primarily in Albania, Kosovo, Montenegro, Serbia, and North Macedonia but also in other parts of the Balkans, along the eastern coast of Italy and in Sicily, as well as by a significant diaspora of Albanians. Although no decisive evidence has been put forward, most linguists and historians suggest that Albanian stems from the ancient Illyrian language (Gray \& Atkinson, 2003; SchwandnerSievers \& Fischer, 2002). Albanian is considered as one of the oldest living languages in the world (e.g., Paçarizi, 2008), used even in the time when Latin and Ancient Greek were being spoken. Albanian language has two dialects, namely Tosk, which is spoken in the more southern parts of

Correspondence to: Rudina Ademi Shala (rudinaademi@gmail.com), Boele De Raad (b.de.raad@rug.nl), or Aliriza Arënliu (aliriza.arenliu@gmail.com)
Albania and it is the basis for standard Albanian, and Gheg, spoken predominantly in the northern regions (Camaj, 1984). The main difference between these two dialects is in sentence formation and pronunciation. The speakers of two dialects understand each other.

While it is an isolate language, Albanian has been strongly affected by other languages throughout history, most notably by Latin, South Slavic, Modern Greek, and Turkish (Gjoleka, 2015). Besides through adoption of words from other languages, its trait-descriptive sediment in language no doubt is influenced by its culture, through ethics, ideological commitments, customs, etc. Up to a certain level these influences may surface in the Albanian vocabulary of personality traits.

\section{The psycho-lexical context of an Albanian study on per- sonality traits}

There is a general acceptance of the validity of dimensions of personality traits in European languages, expressed in the Big Five, with Extraversion, Agreeableness, Conscientiousness, Emotional Stability, and Intellect capturing the most important distinctions among personality traits (De Raad, 2000). This general picture is often accompanied with notions of diversion for certain languages (De Raad \& Mlačić, 2017a). Moreover, studies aimed at comparing factor-structures psychometrically all suggested to be very careful about embracing the Big Five model as the cross-culturally or cross-lingually apt model (Hofstee, Kiers, De Raad, Goldberg, \& Ostendorf, 1997; De Raad, Perugini, \& Szirmák, 1997; De Raad, Barelds, Levert, et al., 2010). 
There is a handful of geographically neighboring languages where lexical studies have been performed. Of two independently performed Italian trait-taxonomic studies, the one study (Caprara \& Perugini, 1994), for example, gave a deviant fifth factor called Conventionality with its opposite pole conveying a "rebellious" version of the Big Five Intellect factor, and the other study (Di Blas \& Forzi, 1998) lacked a clear Intellect factor. A Greek study (Saucier, Georgiades, Tsaousis, \& Goldberg, 2005) gave versions of the Big Five in a six-factor solution, but with different semantic emphases, possibly to be explained by cultural or regional factors. A Croatian study (Mlačić \& \& Ostendorf, 2005), produced an articulate version of the Big Five, while a psycho-lexical study in Serbian (De Raad, Smederevac, Čolović, \& Mitrović, 2018) gave no clear signs of an Intellect factor. Finally, a lexical study in Romanian (Burtăverde \& De Raad, 2019) did also not produce an Intellect factor, except weakly in a factor called Unconventionality, covering traits often found at the negative pole of the Intellect factor.

\section{Lexical approaches and comprehensiveness}

The psycho-lexical approach assumes that "Individual differences that are the most significant in the daily transactions of persons with each other will eventually become encoded into their language" (Goldberg, 1982, p. 204), with trait-descriptive adjectives being seen as the primary form of expressing these differences. Crucial in this approach is to arrive at a comprehensive representation of those trait descriptors.

Since the early pioneering work of Allport and Odbert (1936) who provided an outline for organizing personality descriptors from a lexicon, generally two distinct approaches have been followed to achieve the psycho-lexical aims, referred to as the Dutch and the German approach, respectively (cf., De Raad \& Mlačić, 2017a). The Dutch approach, which started with Brokken (1978), roughly followed a two-phase procedure of which the first phase involved the selection of all adjectives from the dictionary which could possibly apply to a person, and a subsequent removal of terms that did not fit the category of "stable trait" as guided by exclusion categories as specified by Norman (1967). The second phase involved the use of two mold sentences or templates. The first of these was "is [adjective] by nature" to which a trait descriptor had to fit in order to be accepted for further use. For the second, the adjective would be acceptable if it could be an answer to the question "what kind of person is X?"

Typical of the German approach (Angleitner, Ostendorf, \& John, 1990) is that trait descriptors are allowed to be of various kinds, including, for example, words for emotions and for roles. The relevant words are subsequently classified into categories that specify whether a term is a stable trait, a temporary condition, refers to social and reputational aspects, to overt characteristics and appearance, and to (other) terms of limited utility. In comparison to the Dutch approach, this German approach explicitly excluded evaluative terms.

A special distinction between these two approaches concerns the exploitation of different word-categories, an issue not fully dealt with in the psycho-lexical field. Brokken
(1978) only allowed trait descriptive adjectives, while the German approach also allowed nouns as trait descriptors, and distinguished type nouns (e.g., a nerd) and attribute nouns (e.g., friendliness). At a later moment, the Dutch research team started separate studies on personality descriptive verbs (De Raad, Mulder, Kloosterman, \& Hofstee, 1988) and personality descriptive (type-) nouns (De Raad \& Hoskens, 1990), using sentence templates in both these studies. At still a later stage, the Dutch team (De Raad \& Barelds, 2008) included trait descriptors from all possible word-classes in a single analysis. Barelds and De Raad (2015) demonstrated that, for Dutch, particularly the inclusion of trait descriptive verbs added to the differential potential of the trait vocabulary beyond that of trait adjectives.

The central concern with comprehensiveness is not only about an optimal exploitation of the different grammatical categories (adjectives, nouns, verbs), but also about what is to be seen as a trait descriptor. While Allport and Odbert (1936) de-emphasized the use of terms with a predominating evaluative connotation, Tellegen and Waller (1987) suggested to relax that criterion to allow also terms that describe esteem (self- and other-esteem), and such terms are indeed largely evaluative in kind. This evaluation-inclusive approach resulted in two additional factors, namely Positive Valence (PV: excellent, outstanding) and Negative Valence (NV: evil, wicked, disgusting). Both a study in Hebrew (Almagor, Tellegen, \& Waller, 1995) and a study in Spanish (Benet-Martinez \& Waller, 1997) show-cased the Big Seven model, with versions of the Big Five and the additional PV and NV factors.

A recurrent finding in several psycho-lexical studies is the mere extensiveness of the Agreeableness domain, a factor that is often the first one extracted. That vast trait subdomain sometimes gave reason to distinguish separate clusters or facets, leading to adopt additional factors. Ashton, Lee, Perugini, et al. (2004), for example, proposed a Sixfactor model, with roughly the Big Five, plus an additional factor called Honesty-Humility, thus representing one of those possible Agreeableness clusters. Valchev, Van de Vijver, Meiring, et al. (2014) found support for social relational aspects of Agreeableness such as through a cluster of Interpersonal Relatedness traits.

If a cross-cultural perspective is taken, trait-structures with more than three factors tend to be difficult to identify in geographically distant or language-family distinct languages. In such a cross-cultural context, quite a few studies have confirmed the Big Two, maybe best summarized by the meta-concepts Agency and Communion (Bakan, 1966). Agency captures traits from Big Five factors Extraversion and Intellect, and Communion captures traits from especially Big Five Agreeableness and Conscientiousness (e.g., Digman, 1997; DeYoung, 2006; De Raad, Barelds, Timmerman, et al., 2018). De Raad, Barelds, Levert, et al. (2010), and De Raad, Barelds, Timmerman, et al. (2014) gave evidence of a cross-culturally replicable three-factor structure (the Big Three), with Dynamism, Affiliation, and Order, respectively representing kernel characteristics of Extraversion, Agreeableness, and Conscientiousness. To complete this series of structures, the Big One was proposed (Hofstee, 2001; Musek, 2007), capturing the desirable and undesirable personality characteristics at opposite poles of that single factor. 


\section{Aim of the present research}

The first aim of the present research is the construction of a comprehensive list of Albanian personality-relevant terms and to identify those terms that have the capacity to describe dispositional personality characteristics. For this first aim a combination of the Dutch and of the German approaches is followed. The second aim is the structuring of the vocabulary of dispositional traits on the basis ratings from a substantial number of people who have to describe themselves using a representative set of trait descriptive terms. The findings are discussed against the background of the Big Five model, with special interest also in the identification of structures with different numbers of factors (e.g., Big One, Big Two, Big Three, Big Six, and Big Seven).

\section{METHOD}

Related to the aims of this psycho-lexical investigation, the study was performed in two parts. Part 1, comprising the construction of the list of trait descriptors, was done in two steps. The first step involved the selection of all the terms from an Albanian dictionary that could have the capacity to describe personality characteristics, and the second step involved a classification of those terms and the construction of the final selection of terms useful for administration to participants in order to obtain ratings. Part 2 of the study comprised the structuring of the Albanian trait vocabulary based on that final set of trait adjectives.

\section{Part 1: Construction of a personality descriptive list of Albanian trait terms}

An Albanian dictionary (Fjalor i shqipes së sotme, 2002) with approximately 35,000 entrances was used to construct an Albanian vocabulary of trait words. This dictionary is widely used in academic circles. For the selection of relevant words a combination of the Dutch (use of template sentences) and German (inclusion of different kinds of descriptors) was followed.

For the first step of Part I, two judges (the first and third author), independently went through the dictionary with the instruction to select all terms that are useful to describe personality characteristics, or, to put it in Allport and Odbert's (1936) words: terms that have the capacity "to distinguish the behavior of one human being from that of another" (p.24). While the selection of terms included not only adjectives, but also nouns, verbs, and adverbs, for the present study we continued to focus on the adjectives only. The other classes of terms were reserved for future investigation. For each single term that was observed in the dictionary as possibly relevant to describe personality, the judges had to decide about three things:

1) whether a term would fit one of six categories, namely (stable characteristics, states or moods (spiritual states), activities, social roles (functions), abilities or talents, and relationships and impact (influence) (cf., Mlačić \& Ostendorf, 2005)

2 ) whether a term fitted a sentence format. For adjectives this was: How [adjective] am I (cf. Brokken, 1978)
3) whether a term should be excluded based on whether it would (a) be applicable to all (for example, being born, or nationality), (b) be descriptive of a profession, (c) be a physical characteristic (e.g., tall, thin), (d) be a judgment or be predominantly evaluative (good, bad), (e) be a social attitude (racist), and (f) be a special skill/ability (dancer).

The total number of terms, combined for the two judges, which passed through these criteria was 3,478 terms, of which 1,865 were adjectives.

For the second step of Part I, the two judges, independently again, continued to evaluate the set of 1,865 adjectives, the main concern being perspicuity to the participants in the structuring part. First, they rated the adjectives on clarity of meaning, using a 3-point scale, ranging from " 1 " (the meaning of the word is not clear to me), to " 2 " (the meaning of the word became clear after giving it some thought), to " 3 " (the meaning of the word is fairly clear to me). Adjectives that turned out to be clear to both judges (both scored "3") were immediately accepted; those that scored " 1 " by both were removed but only after agreement upon additional discussion. Adjectives that scored " 2 " by one or both of the judges, or scored differently by the two judges, were included or removed after consensus was reached in which clarity was the main issue. This procedure resulted in a firm reduction to a list of 1,089 adjectives to be used in the next steps of the project.

To finalize this second step, the two judges jointly discussed each of the 1,089 adjectives, keeping in mind the main criterion of "differential capacity" and by checking their main meanings and definitions as given in the dictionary. In this process, it was found that quite a few terms conveyed meanings that were not very well distinguishable: they were considered "synonymous", leading to a substantial reduction. Also words that had a predominantly dialectical meaning or a metaphoric meaning were removed. The result of this joint "discussion" step was that 482 were as yet removed, so that 607 rather clear and distinctive trait descriptive adjectives remained for the structuring part of the project.

\section{Part 2: The structuring of the Albanian trait vocabulary}

\section{Participants}

Participants were 497 students from a Department of Psychology and Pedagogy (302 females, 190 males, 5 did not specify gender). The average age of the participants was 20.34 (ranging from 17 to $41 ; S D=3.61$ ). Of the participants 90.4\% declared that Albanian was their native language; the remaining $9.6 \%$ had a different origin (Turkish, Bosniak, Roma, Ashkali, \& Egyptian). Participation in this study was completely voluntary; the participants did receive partial credit for a specific course as a reward.

\section{Procedure}

The questionnaire with 607 adjectives was administered at the University premises. The participants were asked to rate 
Figure 1. Hierarchy of factor-structures based on raw data

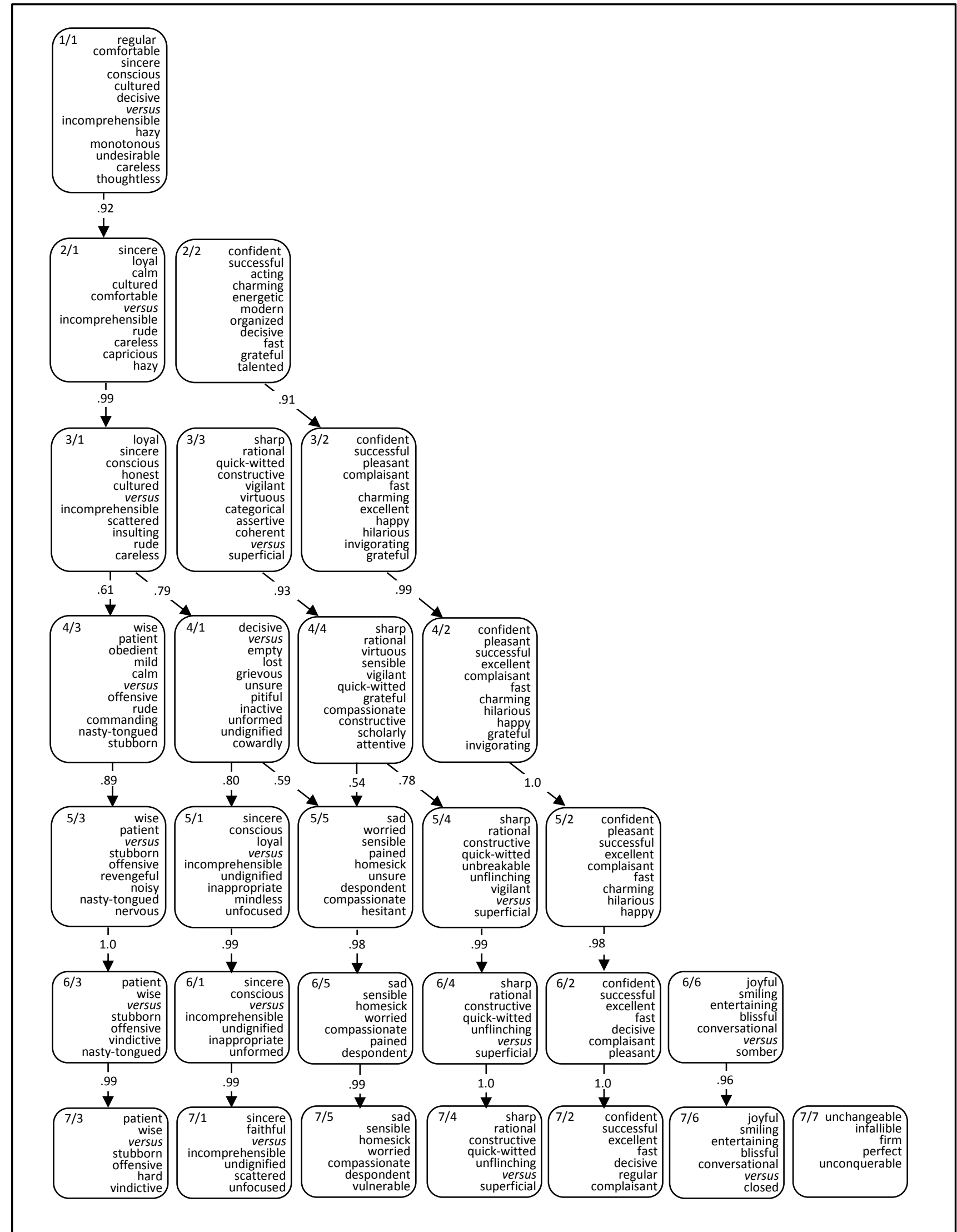

whether the adjectives described themselves as a person. Ratings were done on a 4 point scale, running from " 1 " (not applicable to me), to " 2 " (more not applicable than applicable to me), to " 3 " (more applicable than not applicable to me), to "4" (applicable to me).
After the reduction process in Part 1, there were still terms that might, according to the intuition of two judges, be unclear to the participants. Also, there were terms with perceived discrepancies in evaluation of adjectives. For this reason, as an extra precaution, the two judges compiled a list 
Table 1. Correlations of .45 or higher between components and Big Five marker scales

\begin{tabular}{|c|c|c|c|c|c|c|c|c|c|c|}
\hline \multirow[b]{2}{*}{ Components } & \multicolumn{5}{|c|}{ Raw data } & \multicolumn{5}{|c|}{ Ipsatized data } \\
\hline & $\mathbf{E}$ & $\mathbf{A}$ & C & $\mathbf{S}$ & I & $\mathbf{E}$ & $\mathbf{A}$ & C & $\mathbf{S}$ & I \\
\hline $1 / 1$ & -62 & -82 & -85 & -72 & & 62 & 75 & 75 & 71 & \\
\hline $2 / 1$ & & -83 & -73 & -65 & & -61 & & & -59 & -58 \\
\hline $2 / 2$ & 67 & & 45 & & 77 & & 85 & 54 & & -61 \\
\hline $3 / 1$ & & -82 & -74 & -62 & & -74 & & -58 & -77 & \\
\hline $3 / 2$ & 75 & & & & 55 & & 82 & 48 & & \\
\hline $3 / 3$ & & & & & 63 & & & & & \\
\hline $4 / 1$ & & & -61 & -76 & & -81 & & -47 & -62 & \\
\hline $4 / 2$ & 74 & & & & 55 & & 81 & 46 & & \\
\hline $4 / 3$ & & -78 & & & & & & & & -47 \\
\hline $4 / 4$ & & & & & 56 & & & & & \\
\hline $5 / 1$ & & -48 & -67 & -46 & & -65 & & -53 & -71 & \\
\hline $5 / 2$ & 74 & & & & 54 & & 60 & 55 & & \\
\hline $5 / 3$ & & -76 & & & & 52 & 59 & & & \\
\hline $5 / 4$ & & & & & 63 & & & & & \\
\hline $5 / 5$ & & & & -61 & & & & & & -48 \\
\hline $6 / 1$ & & -49 & -65 & -49 & & -53 & & -45 & -72 & \\
\hline $6 / 2$ & 65 & & 49 & & 56 & & 54 & 61 & & \\
\hline $6 / 3$ & & -75 & & & & & 60 & & & \\
\hline $6 / 4$ & & & & & 61 & & & & & \\
\hline $6 / 5$ & & & & -60 & & & & & & -48 \\
\hline $6 / 6$ & 51 & & & & & -63 & & & & \\
\hline $7 / 1$ & & -49 & -66 & -52 & & & 76 & & & \\
\hline $7 / 2$ & 62 & & 50 & & 60 & & & -70 & -48 & \\
\hline $7 / 3$ & & -75 & & & & & & & 57 & \\
\hline $7 / 4$ & & & & & 62 & & & & & \\
\hline $7 / 5$ & & & & -57 & & -74 & & & & \\
\hline $7 / 6$ & 57 & & & & & & & & & -47 \\
\hline $7 / 7$ & & & & & & & & & & \\
\hline
\end{tabular}

Note: E=Extraversion; A=Agreeableness; $\mathrm{C}=$ Conscientiousness; $\mathrm{S}=$ Emotional Stability; I=Intellect. Decimal points are omitted

of adjectives possibly suffering from these characteristics, and therefore considered to be potentially less familiar to the general population. Thus, a brief glossary with 114 such terms was constructed and made available to the respondents during the administration of the questionnaire in order to provide a consistent explanation for unfamiliar terms. Researchers were present in all administrations and they were supported by 8 assistants who recorded all adjectives for which the participants required further explanation. Adjectives for which more than three times explanation was required were excluded from further analysis. This step involved a reduction with 173 terms, so that further analyses were performed on a data-set with 434 trait adjectives.

\section{RESULTS}

The self-ratings of the 497 participants on the 434 trait adjectives were subjected to Principal Components Analyses plus Varimax rotation, both on raw data and on ipsatized (standardized per person) data. In order to arrive at a number of factors that adequately represented the trait-semantics, use was made of the eigenvalues, of a hierarchy of factorsolutions including correlations between factors from adjacent levels of extraction (cf. Goldberg, 2006), of the interpretability of factors, and of marker-scales of the Big Five factors. For the development of marker-scales, the English translations of the 434 trait-adjectives were identified for their appropriateness to represent the Big Five. Oriented by representations of the Big Five structure markers in Dutch, English, and German (De Raad, 2000), all possible markers were selected from the list of 434 trait-adjectives considered most typical of the Big Five. Of the factor-relevant markers those were selected that produced an optimal internal consistency. The final lists of the Big Five marker adjectives are given in the Appendix. Their respective internal consistencies and numbers of markers were as follows: .83 (19) for Extraversion, .87 (32) for Agreeableness, .82 (18) for Conscientiousness, .77 (20) for Emotional Stability, and .76 (22) for Intellect.

\section{Structure based on raw data}

For the raw data, the first ten eigenvalues were 51.4, 25.2, $10.4,10.0,8.0,6.5,4.9,4.5,4.2$, and 4.0, in combination explaining $22.5 \%$ of the variance, and suggesting maybe four to six components being relevant for further inspection. As an additional help in deciding about the number of components to extract, a hierarchy of factor solutions (cf., Goldberg, 2006) with one up to seven components was constructed (see Figure 1). Figure 1 also includes correlations 
(with a minimum of $|.45|$ ) between components from adjacent levels of extraction. Those correlations showed some splitting of factor-semantics, especially between levels with three to five components. The first five components from the levels with five- to seven-solutions seemed rather stable across those levels. These components were all largely unipolar. Both the six-solution and the seven-solution gave an additional factor $(6 / 6 \& 7 / 7)$, unrelated to factors at previous levels, and both accounting for $1.7 \%$ of the variance.

The first unrotated component (1/1; explaining $11.8 \%$ of the variance) loaded traits conveying organization, structure, sociability, morality, and their opposites. It correlated substantially (all above .60) with the marker-scales for Agreeableness, Conscientiousness, Emotional Stability, and Extraversion (see Table 1, raw data part), thus apparently forming a general Evaluation factor (the Big One).

The two-component solution seemed to represent the Big Two, with component $2 / 1$ loading traits expressing morality and discipline, and correlating substantially (above .60) with marker-scales for Agreeableness, Conscientiousness, and Emotional Stability. The second component (2/2) conveyed confidence, energy, and being successful, and it correlated highest with the marker-scales for Intellect and Extraversion.

Of the three-component solution, the components $3 / 1$ and $3 / 2$ virtually repeated the Big Two, but with less emphasis on traits of Intellect in component $3 / 2$. The third component $(3 / 3)$ seemed to be a rather articulate version of Intellect, with traits such as sharp, rational, quick-witted, and with a substantial correlation with the Intellect markerscale.

At the four-component level components $4 / 1$ and $4 / 3$ formed a split of component 3/1, with 4/3 representing Agreeableness and 4/1 emphasizing mainly negative traits of Conscientiousness. The other two components $(4 / 2 \&$ $4 / 4$ ) repeated the components $3 / 2$ and $3 / 3$.

The five-factor solution appeared to be an identifiable version of the Big Five, each with the highest correlation with one of the Big Five marker-scales. Three of the components $(5 / 1,5 / 3, \& 5 / 5)$, loaded, however, largely with traits from the negative poles of the components. The Big five returned at both the six-component and the seven-component level, with the additional components $6 / 6$ and $7 / 6$ both representing traits of Extraversion, and a component 7/7 possibly representing some traits (e.g., perfect, infallible) of Positive Valence.

\section{Structure based on ipsatized data}

The first ten eigenvalues of the Principal Components Analysis based on ipsatized data were 25.8, 14.9, 13.6, 9.2, 7.6, $6.4,5.5,5.4$. 4.9, \& 4.4, together explaining $22.5 \%$ of the variance, and suggesting five or six components to extract. We constructed a hierarchy of factors with one up to seven components as an aid in deciding about the adequate number of components to extract (Figure 2). Again, the different factor structures were presented in a hierarchy, and they were used to help identify a possible Big One, a Big Two, a Big Three, a Big Six, and a Big Seven. Also in this case, correlations with Big Five marker-scales were calculated.
The first unrotated component based on ipsatized data again seemed to present a general Evaluation factor, correlating with Big Five marker-scales for Agreeableness, Conscientiousness, Emotional Stability, and Extraversion (see Table 1, ipsatized data part).

The two-solution again paralleled the Big Two, with 2/1 emphasizing independence, energy, and confidence, and $2 / 2$ emphasizing kindness, fairness, and understanding. The highest correlations with the marker-scales were with Extraversion and Agreeableness, respectively.

Of the three-solution, component $3 / 1$ repeated $2 / 1$; the correlations with the marker-scales indicates a stronger emphasis on Emotional Stability. Component 3/2 reflected mainly Agreeableness traits. Component 3/3 seemed to represent traits of Intellect (e.g., sharp, rational, quick-witted), though its correlation with the Intellect marker-scale remained below the criterion of .45 as presented in Table 1 .

The components $4 / 1$ and $4 / 2$ repeated $3 / 1$ and $3 / 2$ of the three solution. Component $4 / 3$ is an Intellect-related factor, now also supported by a correlation of .48 with the pertaining marker-scale. Component 4/4 appeared unrelated to the Big Five marker-scales. Its content seemed to represent traits of Negative Valence.

With five components, the differences with the previous level were especially in two components that are both related to Agreeableness: 5/2 combined with features of Conscientiousness, thus conveying morality, and 5/3 combined with Extraversion, thus conveying sociability.

With six components, $6 / 2$ was similar to the previous $5 / 2$ but with a stronger emphasis on Conscientiousness. The component 5/3 seemed to split into an Agreeableness component and an Extraversion component.

At the level with seven components, the change was an additional component, unrelated to the Big Five markerscales, and seemingly related to Positive Valence.

\section{Comparison of the structures based on raw data and those based on ipsatized data}

The ipsatization had a moderate effect in removing, presumably mostly acquiescence-related, variance, going from $29,7 \%$ to $22,5 \%$ with ten components extracted. The differences between the contents of the components at the seven levels of extraction for the raw data and the ipsatized data turned out to be rather small. In the raw-data based structures, the five-components solution was easily interpretable as the Big Five. In the ipsatized data based structures, the Big Five were identifiable as well, most clearly in the sevencomponent solution. In fact, the correlations between those five (raw) and seven (ipsatized) components were substantial: 0.75 between raw $5 / 1$ and ipsatized $7 / 2$ (representing Conscientiousness), -0.52 between raw $5 / 2$ and ipsatized $7 / 5$ (representing Extraversion), -0.89 between raw 5/3 and ipsatized 7/1 (representing Agreeableness), -0.86 between raw $5 / 4$ and ipsatized 7/6 (representing Intellect), and -0.68 between raw 5/5 and ipsatized 7/3 (representing Emotional Stability). The ipsatized seven-component solution, in addition, gave evidence of a Negative Valence factor and of a Positive Valence factor. We therefore suggest the ipsatized 
Figure 2. Hierarchy of factor-structures based on ipsatized data

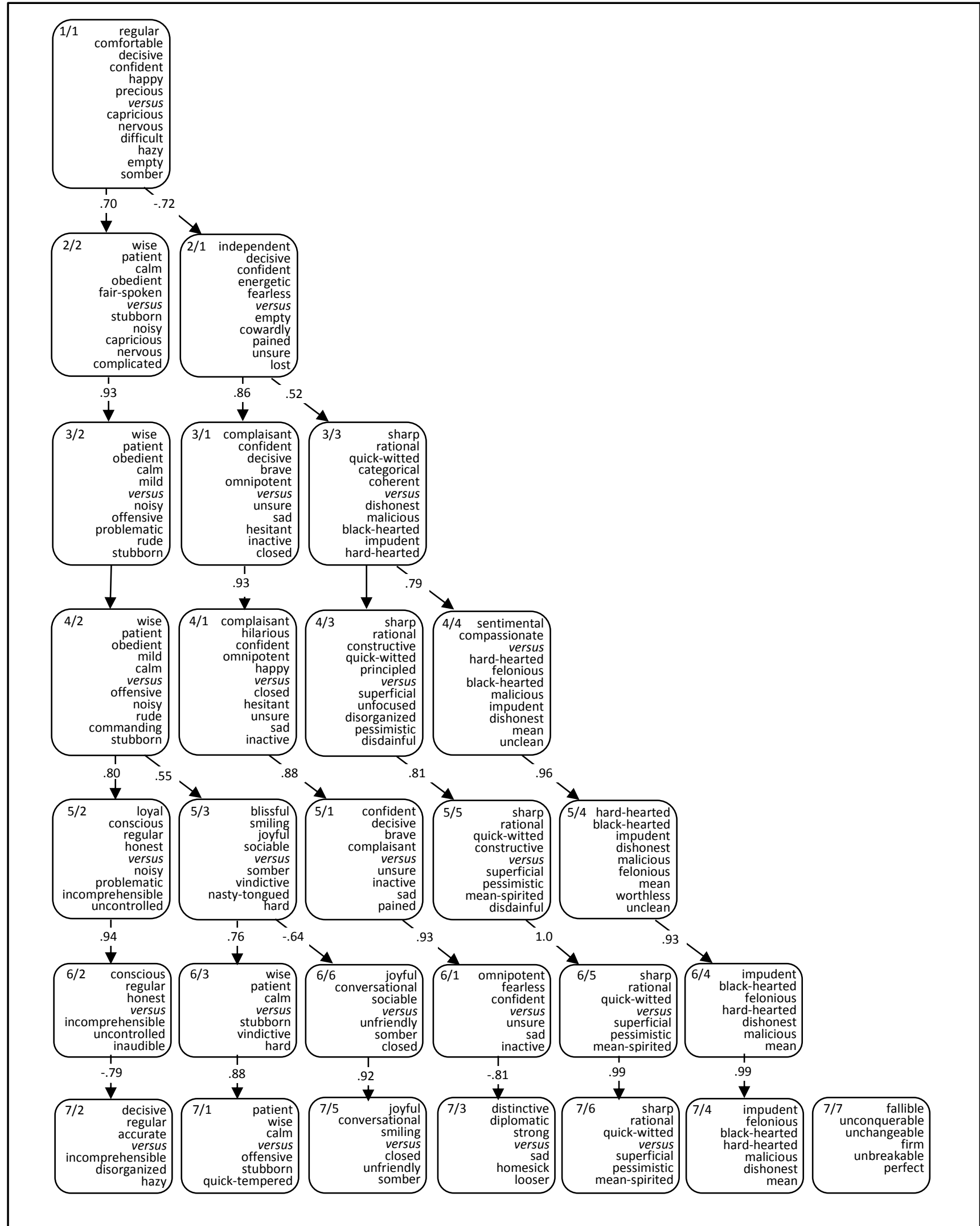

based seven-component solution to summarize best the semantic trait domain in the Albanian personality language. The contents of this seven-solution are presented in Table 2 , with factor 7/1 be called Agreeableness and factor 7/2 Con- scientiousness; factor $7 / 3$ comes closest to Emotional Stabil ity, factor $7 / 4$ is typical of Negative Valence, factor $7 / 5$ is Extraversion, factor 7/6 Intellect, and finally factor 7/7 represents Positive Valence. 
Table 2. Description of contents of seven-factor solution based on ipsatized data

7/1 (+) patient, wise, calm, obedient, fair-spoken, understandable, reflective, comfortable, disciplined, mild, loyal, cultured, kind, generous, conscious, mature, dear, well-intentioned, remissive, imperturbable

(-) offensive, stubborn, quick-tempered, noisy, nervous, vindictive, hard, capricious, nasty-tongued, problematic, rancorous, aggressive, severe, impulsive (2x), commanding, rude, ill-tempered, jealous, wild, reproachful, disorderly, embittered, insulting, rowdy, difficult (2x), arrogant (3x), threatening, self-conceited, explosive, complicated, irresistible, unbearable

7/2 (+) decisive (2x), regular, accurate, acting, precious, clear, confident, focused, realistic, attentive, fluent, conscientious, skillful, organized, serious, open-eyed, planning, honest, prepared, willing, moral, sincere

(-) incomprehensible, disorganized (2x), hazy, unfocused $(2 x)$, thoughtless, careless, uncontrolled (2x), inaudible, empty, unsure, tempting, uncertain, inattentive, unstable, scattered, unconscious, immature, inappropriate, somber, weird, disobedient

7/3 (+) distinctive, diplomatic, strong, brave, vigorous, dominant, versatile, fearless, commanding, complaisant, intellectual, managing, happy, grateful, victorious, combative, successful

(-) sad, homesick, looser, sensible, vulnerable, compassionate, lost, scared, inactive, cowardly, fragile, hesitant, pained, despondent, broken, weak, worried, hearty, naïve, shy

7/4 (-) impudent (2x), felonious, black-hearted (2x), hard-hearted, malicious (2x), dishonest, mean, unclean, worthless, mindless, incapable, unkind, deceitful, betrayer, unfaithful, unmerciful, harmful, ungrateful, unrealistic, undignified, unserious

7/5 (+) joyful, conversational, smiling, entertaining, blissful, hilarious, sociable, cheerful, enthusiastic, pleasant, chatty, playful, friendly, invigorating, charming, pleased, open, artistic, modern

(-) closed, unfriendly, somber, unpleasant, unapproachable, rigid, quiet, monotonous

7/6 (+) sharp, rational, quick-witted, constructive, scholarly, unflinching, virtuous, principled, unconditional, vigilant, analytical, aesthetical, coherent, saintly, assertive, habitual, effective, sincere, encouraging, impartial, versatile, devout (-) superficial, pessimistic, mean-spirited, disdainful, cruel, hysterical, ungenerous, funny/ridiculous

\section{DISCUSSION}

Structuring personality traits according to the psycho-lexical approach has been performed in some 30 languages, of which about two-third took place in European languages (cf. De Raad \& Mlačić, 2017b). The predominant model of personality traits, the Big Five, has been identified in several of those languages, but quite a few studies showed diversity in the contents of one or more of the factors. In that context it is important to strive after psycho-lexical studies performed in the largest possible set of languages. Albanian is of special interest because it is a relatively isolate language with a history longer than most other European languages, yet located in the European cultural context.

The present study on the trait structure in Albanian was done according to a rather standard schedule, a combination of Dutch and German approaches regarding the selection of trait terms in the lexicon, and a generally accepted procedure concerning the actual structuring of the trait terms on the basis of self-ratings. Ultimately, it was concluded that a seven-factor solution was the most appropriate one to represent the trait semantics in the Albanian language most optimally. The contents of that structure look very much like the Big Five, complemented by Negative Valence and Positive Valence, and comes therefore also close to the Big Seven model (Almagor, Tellegen, \& Waller, 1995; Benet \& Waller, 1995).

In addition, the contents of a single (first) unrotated factor seem to represents the evaluative traits as suggested for the Big One, and the two-factor structure represents the Big Two. A Big Three does not appear in a straightforward three-factor solution, and the Big Five show up in six-and seven factor solutions. An Honesty cluster of traits does not appear in any of the factor solutions.

One might expect the strong appearance of the Valence factors, especially Negative Valence to be the result of an unrestricted approach in the selection of trait terms from the lexicon, as advised by Almagor et al. (1995), but no particular effort was made to include non-typical, evaluationloaded, esteem-related terms in the selection. Moreover, part of the selection-procedure was the explicit exclusion of evaluative terms. A more devoted study on this aspect, combined with data expressing the trait descriptive function of nouns, verbs, and adverbs, may throw some light on this matter. Cultural conditions often play a role in the appreciation of personality, and this cultural aspect may also have had its influence on the use and role of (evaluative aspects) of the different types of trait descriptive words.

A point of critique in this study could be seen in the dictionary that was used, which contained no more than 35,000 entrances; this could be read as a poor starting point. The number of entrances in dictionaries is, however, mainly determined by the number of words for objects, that is nouns. The set of adjectives is usually rather stable, from less comprehensive to more comprehensive dictionaries. Moreover, more restricted dictionaries tend to be built up around the more useful words; obsolete words form the first candidates to be excluded from such dictionaries.

Another point of critique may be seen in the fact that the study was performed only in Kosovo, not including Albania. The Albanian language that is used and its semantics may be affected by a dialectic form as it has two main dialects 
Gheg and Tosk. The dictionary used in this study uses official Albanian language which is heavily relied on Tosk dialect, whereas Albanian speakers in Kosovo use the Gheg dialect. Notwithstanding such difficult to identify languagecultural and dialect influences, the final trait structure that was found, is very much in agreement to what has been found elsewhere in Europe.

The Big Five can well be discerned in the six- and sevenfactor solutions. Further analyses, in which this Albanian structure is compared, in terms of contents and psychometrically, to other trait-taxonomically based structures in different languages, may possibly lead to differences in emphasis in what may be considered as the most appropriate Albanian trait structure, in the context of surrounding languages and cultures.

It seems fair to conclude that the Big Five is identified in the Albanian language, and so are the Big One and the Big Two. Moreover, it seems that Negative Valence and to a lesser extent Positive Valence, are also part of the Albanian personality descriptive vocabulary.

\section{ETHICAL COMPLIANCE SECTION}

The authors have no funding to disclose.

All procedures performed in this study were in accordance with the ethical standards of the Faculty Council of the Philosophical Faculty of the University of Prishtina and with the 1964 Helsinki Declaration and its later amendments or comparable ethical standards.

The authors declare they have no conflict of interest.

An Informed Consent statement was not used. The participants were invited to take part in this study on a voluntary basis, and only a questionnaire was used to be answered anonymously.

\section{REFERENCES}

Allport, G.W. \& Odbert, H.S. (1936). Trait-Names. A psycholexical study. Psychological Monographs, 47. (Whole No. 211). Almagor, M., Tellegen, A., \& Waller, N. (1995). The Big Seven model: A cross-cultural replication and further exploration of the basic dimensions of natural language of trait descriptions. Journal of Personality and Social Psychology, 69, 300-307.

Angleitner, A., Ostendorf, F. \& John, O.P. (1990). Towards a taxonomy of personality descriptors in German. A psycholexical study. European Journal of Personality, 4, 89-118.

Ashton, M.C., Lee, K., Perugini, M., Szarota, P., De Vries, R.E., Di Blas, L.,. Boies, K., \& De Raad, B. (2004). A six-factor structure of personality-descriptive adjectives: Solutions from psycholexical studies in seven languages. Journal of Personality and Social Psychology, 86, 356-366.

Bakan, D. (1966). The duality of human existence: Isolation and communion in Western man. Boston: Beacon.

Barelds, D.P.H., \& De Raad, B. (2015). The role of wordcategories in trait-taxonomy: Evidence from the Dutch personality taxonomy. International Journal of Personality Psychology, 1, 15-25.

Benet, V., \& Waller, N.G. (1995). The Big Seven factor model of personality description: Evidence for its cross-cultural generality in a Spanish sample. Journal of Personality and Social Psychology, 69, 701-718.

Benet-Martinez, V., \& Waller, N.G. (1997). Further evidence for the cross-cultural generality of the Big Seven factor model:
Indigenous and imported Spanish personality constructs. Journal of Personality, 65, 567-598.

Brokken, F.B. (1978). The language of personality. Unpublished doctoral dissertation. Meppel, The Netherlands: Kripps.

Burtăverde, V., \& De Raad, B. (2019). Taxonomy and structure of the Romanian personality lexicon. International Journal of Psychology, 54, 377-387.

Camaj, M. (1984). Albanian grammar: With exercises, chrestomathy and glossaries. Wiesbaden: Otto Harrassowitz Verlag.

Caprara, G.V. \& Perugini, M. (1994). Personality described by adjectives: The generalizability of the Big Five to the Italian lexical context. European Journal of Personality, 8, 357-369.

De Raad, B. (2000). The Big Five personality factors: The psycholexical approach to personality. Göttingen: Hogrefe \& Huber Publishers.

De Raad, B., \& Barelds, D.P.H. (2008). A new taxonomy of Dutch personality traits based on a comprehensive and unrestricted list of descriptors. Journal of Personality and Social Psychology, 94, 347-364.

De Raad, B. \& Hoskens, M. (1990). Personality-descriptive nouns. European Journal of Personality, 4, 131-146.

De Raad, B., \&., Mlačić, B. (2017a). The Lexical Foundation of the Big Five Factor Model. In T.A. Widiger (Ed.), The Oxford Handbook of the Five Factor Model (pp. 191-216). Oxford University Press, New York.

De Raad, B., \&., Mlačić, B. (2017b). Psycholexical Studies of Personality Structure across Cultures. In A.T. Church (Ed.), The Praeger Handbook of Personality across Cultures, Vol. 1: Trait Psychology across Cultures (pp. 161-192). Praeger, USA.

De Raad, B., Mulder, E., Kloosterman, K., \& Hofstee, W.K.B. (1988). Personality-decriptive verbs. European Journal of Personality, 2, 81-96.

De Raad, B., Perugini, M., \& Szirmák, Z. (1997). In pursuit of a cross-lingual reference structure of personality traits: Comparisons among five languages. European Journal of Personality, 11, 167-185.

De Raad, B., Smederevac, S., Čolović, P., \& Mitrović, D. (2018). Personality traits in the Serbian language: Structure and procedural effects. Journal of Research in Personality, 73, 93110.

De Raad, B., Barelds, D.P.H., Levert, E., Ostendorf, F., Mlačić, B., Di Blas, L., et al. (2010). Only three factors of personality description are fully replicable across languages: A comparison of 14 trait taxonomies. Journal of Personality and Social Psychology, 98, 160-173.

De Raad, B., Barelds, D.P.H., Timmerman, M.E., De Roover, K., Mlačić, B., \& Church, A.T. (2014). Towards a pan-cultural personality structure: Input from 11 psycho-lexical studies. European Journal of Personality, 28, 497-510.

De Raad, B., Barelds, D.P.H., Mlačić, B., Di Blas, L, Hřebíčková, M., Ostendorf, F, Szirmák, Z., \& Szarota, P. (2018). Take 2 personality factors: A study of two fundamental ways of trait differentiation in eleven trait taxonomies. International Journal of Personality Psychology, 4, 39-55.

DeYoung, C. G. (2006). Higher-order factors of the Big Five in a multi-informant sample. Journal of Personality and Social Psychology, 91, 1138-1151.

Di Blas, L. \& Forzi, M. (1998). An alternative taxonomic study of personality-descriptive adjectives in the Italian language, European Journal of Personality, 12, 75-101.

Digman, J.M. (1997). Higher-order factors of the Big Five. Journal of Personality and Social Psychology, 73, 1246-1256.

Fjalor $i$ shqipes së sotme (2002). [Dictionary of Today's Albanian], Akademia e Shkencave e Shqipërisë Instituti i Gjuhësisë dhe i Letërsisë, Botimi i dytë i ripunuar [Albanian Academy of Sciences, Institute of Linguistics and Literature, $2^{\text {nd }}$ edition. Toena, Tirana.

Fortson IV, B.W. (2011). Indo-European language and culture: An introduction (Vol. 30). John Wiley \& Sons. 
Goldberg, L.R. (1982). From ace to zombie. Some explorations in the language of personality. In: C.D. Spielberger \& J.N. Butcher (Eds.), Advances in Personality Assessment (Vol. 1, pp. 203234). Hillsdale, N.J: Lawrence Erlbaum.

Goldberg, L.R. (2006). Doing it all bass-ackwards: The development of hierarchical factor structures from the top down. Journal of Research in Personality, 40, 347-358.

Gjoleka, M. (2015). The Albanian language in the face of globalization challenges: The issue of borrowings. European Scientific Journal, 11, 146-164.

Gray, R.D. \& Atkinson, Q.D. (2003). Language-tree divergence times support the Anatolian theory of Indo-European origin. Nature, 426, 435-439.

Hofstee, W.K.B. (2001). Intelligence and personality: Do they mix? In J.M. Collis \& S. Messick (Eds.), Intelligence and Personality: Bridging the Gap in Theory and Measurement (pp. 43-60). Mahwah, New Jersey: Lawrence Erlbaum.

Hofstee, W.K.B., Kiers, H.A.L., De Raad, B., Goldberg, L.R., \& Ostendorf, F. (1997). A comparison of Big-Five structures of personality traits in Dutch, English, and German. European Journal of Personality, 11, 15-31.

Klein, J., Joseph, B., \& Fritz, M. (2018). Handbook of Comparative and Historical Indo-European Linguistics. Berlin: De Gruyter Mouton.

Mlačić, B., \& Ostendorf, F. (2005). Taxonomy and Structure of Croatian Personality-descriptive Adjectives. European Journal of Personality, 19, 117-152.
Musek, J. (2007). A general factor of personality: Evidence for the Big One in the Five-Factor model. Journal of Research in Personality, 41, 1213-1233.

Norman, W.T. (1967). 2800 personality trait descriptors: Normative operating characterstics for a university population. Department of Psychology, University of Michigan, Ann Arbor. Paçarizi, R. (2008). Albanian Language. Thesis Kosova, 1, 93-108.

Peabody, D., \& Goldberg, L.R. (1989). Some determinants of factor structures from personality-trait descriptors. Journal of Personality and Social Psychology, 57, 552-567.

Saucier, G., Georgiades, S., Tsaousis, I., \& Goldberg, L.R. (2005). The factor structure of Greek personality adjectives. Journal of Personality and Social Psychology, 88, 856-875.

Schwandner-Sievers, S. \& Fischer, B.J. (2002). Albanian identities: Myth and history. Bloomington: Indiana University Press.

Tellegen, A., \& Waller, N.G. (1987). Re-examining basic dimensions of natural language trait descriptors. Paper presented at the 95th Annual Convention of the American Psychological Association, New York.

Valchev, V.H., van de Vijver, F.J.R., Meiring, D., Nel, J.A., Hill, C., Laher, S., \& Adams, B.G. (2014). Beyond agreeableness: Social-relational personality concepts from an indigenous and cross-cultural perspective. Journal of Research in Personality, $48,17-32$

Received October 13, 2020 Accepted December 17, 2020 


\section{APPENDIX}

\section{Markers of the Big Five factors}

\section{Extraversion}

active, cheerful, smiling, energetic, vigorous, joyful, open, happy, conversational, enthusiastic, sociable, acting, entertaining versus

closed, somber (2x), passive, inactive, lonely.

\section{Agreeableness}

loyal, generous (2x), fair, patient, supportive, friendly, honest, sincere, kind, kindhearted, mild versus

aggressive, hostile, arrogant (3x), egoistic, deceitful, quick-tempered, commanding (2x), greedy, offensive, unfriendly, selfish, ungenerous, ill-tempered, vindictive, rancorous, short-tempered, hard-hearted.

\section{Conscientiousness}

disciplined, organized, focused, planning, accurate, conscientious, diligent

versus

messy, lazy, chaotic, careless, unclean, disorganized (2x), irresponsible, unfocused, disorderly, scattered.

\section{Emotional Stability}

strong, brave, confident, fearless, decisive $(2 \mathrm{x})$

versus

anxious, hysterical, unstable, touchy, nervous, uncontrolled, uncertain, sad, vulnerable, cowardly, sentimental, worried, depressed, melancholic.

\section{Intellect}

analytical, reasonable, scholarly, aesthetical, philosophical, reflective, versatile $(2 x)$, intellectual, constructive, creative, critical, cultured, smart, quick-witted, sharp, original, rational, excellent (2x), talented,

versus

narrow-minded. 